\title{
Ectopic adiposity and cardiometabolic health in COPD
}

This article was published in the following Dove Press journal:

International Journal of COPD

\author{
Valérie Coats' \\ Jean-Pierre Després \\ Natalie Alméras' \\ Mickaël Martin' \\ Don D Sin² \\ Rémi Rabasa-Lhoret ${ }^{3}$ \\ Éric Larose' \\ Wan C Tan ${ }^{2}$ \\ Jean Bourbeau ${ }^{4}$ \\ François Maltais' \\ On behalf of the CanCOLD \\ Collaborative Research \\ Group and the Canadian \\ Respiratory Research \\ Network \\ 'Centre de Recherche, Institut \\ Universitaire de Cardiologie et de \\ Pneumologie de Québec-Université \\ Laval, Québec, QC, Canada; \\ ${ }^{2}$ University of British Columbia, \\ Vancouver, BC, Canada; ${ }^{3}$ Institut de \\ Recherches Cliniques de Montréal, \\ Département de Nutrition et Service \\ d'Endocrinologie, Centre Hospitalier \\ de l'Université de Montréal, \\ Montréal, QC, Canada; ${ }^{4}$ Respiratory \\ Epidemiology and Clinical Research \\ Unit, Research Institute of the McGill \\ University Health Centre, Montreal, \\ QC, Canada
}

Correspondence: François Maltais Centre de Pneumologie, Institut Universitaire de Cardiologie et de Pneumologie de Québec, 2725 Chemin Sainte-Foy, Québec (QC), GIV 4G5, Canada

Tel + I 4186564762

Email francois.maltais@fmed.ulaval.ca
Rationale: Obesity/overweight is the most prevalent body composition abnormality in COPD. However, little is known about the impact of fat distribution on cardiometabolic health in COPD.

Objective: To study the associations between ectopic adiposity, cardiometabolic health, and COPD.

Methods: A total of 263 subjects ( 166 males; age $=65 \pm 9$ years) were randomly selected from the general population. Subjects were classified as non-COPD controls and COPD, according to the Global initiative for chronic Obstructive Lung Disease (GOLD) classification, and the presence of cardiometabolic comorbidities was recorded. Ectopic fat accumulation was documented from computed tomography measurements of visceral adipose tissue cross-sectional areas and muscle mean attenuation, assessed at L4-L5. Blood glucose, lipid, and adipokine profiles were also evaluated.

Results: After correcting for age, sex, and tobacco exposure, visceral adipose tissue crosssectional area was higher in GOLD 2+ compared to GOLD 1 individuals. Consistent with this, mean muscle tissue attenuation was lower in GOLD 2+ vs GOLD 1 and non-COPD controls $(P<0.001)$. In multiple regression models, visceral adipose tissue cross-sectional area was strongly associated with hypertension $(P<0.001)$ and diabetes $(P<0.001)$, while muscle attenuation was associated with coronary artery disease $(P<0.001)$. Blood glucose, lipid, and adipokine profiles were similar across groups with the exception of leptin level which was higher in GOLD 2+ subjects compared to GOLD 1 and controls.

Conclusion: GOLD 2+ COPD was associated with ectopic fat accumulation which modulated cardiometabolic health.

Keywords: chronic obstructive pulmonary disease, obesity, abdominal, comorbidity, ectopic adiposity, cardiometabolic health

\section{Introduction}

Consistent with the worldwide obesity epidemic, overweight/obesity is now the most prevalent body composition abnormality in patients with COPD.${ }^{1,2}$ In epidemiological studies, obesity is defined based on body mass index (BMI) but there is a need to refine the clinical evaluation of obesity by studying fat distribution. ${ }^{3}$ For example, cardiometabolic diseases, such as hypertension, coronary and peripheral artery diseases, and diabetes, are more closely associated to ectopic adiposity, in which fat accumulates in the abdomen or in normally lean organs such as the skeletal muscles, than to BMI. ${ }^{4}$ As such, there is a growing interest to better characterize body fat distribution in patients with COPD and to evaluate whether it is associated with adverse health consequences. We and others have recently reported that ectopic fat accumulates in patients with COPD.$^{5-7}$ However, estimating to which extent ectopic adiposity is 
related to COPD from these studies is problematic because enrolled participants were not necessarily representative of the general population, thus introducing potential biases in the estimation of the magnitude of the problem.

COPD is also intimately associated with the occurrence of cardiovascular ${ }^{8,9}$ and metabolic diseases (insulin resistance and diabetes), ${ }^{10,11}$ leading to increased all-cause and cardiovascular mortality in patients with COPD, ${ }^{6}$ which may even be more frequent than COPD-related deaths. ${ }^{12}$ Again, conclusions about the association between impaired cardiometabolic heath and COPD may be influenced by selection biases in studies where participants were selected from existing patient databases or because of their interactions with medical teams. Considering the detrimental effects of ectopic adiposity on cardiometabolic health in the general population ${ }^{4}$ and that this form of obesity could be increased in COPD, ${ }^{5-7}$ the possibility exists that ectopic adiposity could also modulate cardiometabolic health in COPD and be responsible, in part, for the cardiometabolic comorbidities seen in COPD.

The present study was embedded in the Canadian Cohort Obstructive Lung Disease (CanCOLD) study, a prospective longitudinal study for COPD with random population sampling. The research questions were as follows: 1) does ectopic fat accumulate in individuals with COPD identified through random sampling of the population; 2) is ectopic fat accumulation associated with adverse cardiometabolic health consequences in this population?

\section{Methods}

\section{Study design and participants}

All CanCOLD participants in two CanCOLD study centers (Montreal and Quebec City) were recruited for this substudy. CanCOLD (ClinicalTrials.gov: NCT00920348) is a longitudinal cohort study based on random population sampling over the age of 40 years in nine Canadian cities. CanCOLD study design and protocol have been previously reported. ${ }^{13}$ Study participants underwent the standard CanCOLD assessment procedures which provide information about patients' characteristics (age, race, sex, smoking history), medical history, body weight and height, and pulmonary function. To assess for cardiometabolic comorbidities, subjects completed a standardized questionnaire where the following question was asked: "Has a doctor or other health care provider ever told you that you had any of the following conditions?": hypertension, diabetes, coronary artery disease (including myocardial infarction, angina, coronary artery bypass, and angioplasty), and peripheral artery disease (including stroke, claudication, and peripheral artery surgery). ${ }^{13}$ In addition, hypertension, diabetes, and coronary artery disease were considered present in participants taking antihypertensive, antianginal, and antidiabetic medications. Study participants also completed specific procedures for the purpose of this substudy: 1) measurements of waist and hip circumferences, 2) blood sampling to determine glucose, lipid, adipokine, and high-sensitivity C-reactive protein (Hs-CRP) profiles, and 3) a computed tomography (CT) abdominal scan at L4-L5 level to quantify body composition. Chest CT, which is already a part of the routine CanCOLD procedures, was used to assess liver density and to quantify coronary artery calcification. All patients provided written informed consent and the study was approved by ethics committees of participating centers. CanCOLD steering and scientific committees approved the substudy protocol.

Study participants were divided according to the pulmonary function testing results: 1) control subjects with a postbronchodilator $\mathrm{FEV}_{1}>80 \%$ predicted value and $\mathrm{FEV}_{1} / \mathrm{FVC}$ ratio $\geq 0.7 ; 2$ ) patients with COPD with a post-bronchodilator $\mathrm{FEV}_{1} / \mathrm{FVC}$ ratio $<0.7$ were further classified according to the Global initiative for chronic Obstructive Lung Disease (GOLD) airflow limitation classification scheme into GOLD 1, with an $\mathrm{FEV}_{1} \geq 80 \%$ predicted and GOLD 2+ with an $\mathrm{FEV}_{1}<80 \%$ predicted.

\section{Body composition, liver density, and coronary artery calcification assessment}

Abdominal fat and muscle (psoas, paraspinal, and abdominal wall muscles) tissue cross-sectional areas and densities were quantified from the L4-L5 CT according to standardized techniques. ${ }^{14}$ Images were analyzed using a specialized image analysis software (Slice-O-Matic; Tomovision, Montreal, QC, Canada), without knowledge of the clinical status of the subjects. Adipose and muscle tissue cross-sectional areas $\left(\mathrm{cm}^{2}\right)$ were measured using an attenuation range of -190 to -30 Hounsfield units (HU) and of -29 to $130 \mathrm{HU}$, respectively. The mean attenuation value in $\mathrm{HU}$ of each structure was generated. Studies in animals have indicated that a lower attenuation (expressed as lower HU values) is associated with increased tissue fat content. ${ }^{15}$ To avoid subjectivity in the separation between subcutaneous and visceral adipose tissues, these two fat tissues were separated from each other midway in the thickness of abdominal wall muscles. Body composition parameters were obtained with methodology commonly applied in our laboratory, with high levels of intra- and interobserver agreement. ${ }^{5}$ Using the low-dose volumetric CT scan of the chest at full inspiration obtained in CanCOLD, ${ }^{16}$ 
coronary artery calcification, a surrogate of coronary artery disease, and liver density, ${ }^{17}$ a marker of fat liver infiltration, were quantified, according to standardized techniques. ${ }^{18,19}$

\section{Glucose, lipid, and adipokine profiles}

Blood samples were collected in the morning after a 12-hour fast to determine the levels of glucose, insulin, total cholesterol, LDL-cholesterol, HDL-cholesterol, apolipoproteins (apoAI and apoB), triglycerides, Hs-CRP, hemoglobin A1c, and liver enzymes (aspartate aminotransferase [AST], alanine aminotransferase [ALT], gamma glutamyl-transferase [GGT]). All analyte levels were determined in plasma and whole blood using automated techniques (Roche Diagnostics, Hoffman-La Roche Ltd., Basel, Switzerland). Glucose, total cholesterol, HDL-cholesterol, LDL-cholesterol, triglycerides, and liver enzymes (AST, ALT, GGT) were measured by enzymatic in vitro test. Apolipoproteins (apoAI and apoB) and Hs-CRP were measured using immunoturbidimetric assay. Insulin was determined using electrochemiluminescence immunoassay. Hemoglobin A1c was measured by turbidimetric inhibition immunoassay for hemolyzed whole blood. Plasma levels of adiponectin, leptin, ghrelin, and resistin were quantified using sensitive immunoassay kits, all available commercially (R\&D Systems Inc., Minneapolis, MN, USA: adiponectin, leptin, and resistin; EMD Millipore, Billerica, MA, USA: ghrelin).

\section{Statistical analyses}

Subjects' characteristics were compared between controls and the two groups of individuals with COPD, using ANOVA models for continuous variables and log-linear models for discrete variables. BMI, coronary artery calcification scores, total and HDL-cholesterol, triglycerides, leptin, adiponectin, ghrelin, resistin, and Hs-CRP were analyzed on a $\log _{10}$ scale because they had a log-normal distribution. Except for subjects' characteristics and lung function parameters appearing in Table 1, all remaining analyses were controlled for age, sex, and cumulative smoking history (pack-years). Betweengroup comparisons were conducted using a multivariate analysis of covariance model (MANCOVA), with age, sex, and pack-years included as covariates. When a significant effect of groups or subgroups was identified, univariate analyses of covariance models (ANCOVA) were performed to investigate which variables were different, followed by least significant difference-protected multiple comparisons to differentiate

Table I Baseline characteristics by group

\begin{tabular}{|c|c|c|c|c|c|c|c|}
\hline & $\begin{array}{l}\text { Control } \\
\text { subjects } \\
(n=I \mid 9)\end{array}$ & $\begin{array}{l}\text { GOLD I } \\
\text { COPD } \\
(n=70)\end{array}$ & $\begin{array}{l}\text { GOLD } 2 \\
\text { COPD } \\
(n=74)\end{array}$ & $\begin{array}{l}P \text {-value } \\
\text { Overall }^{b}\end{array}$ & $\begin{array}{l}\text { P-value } \\
\text { GOLD I vs } \\
\text { controls }\end{array}$ & $\begin{array}{l}P \text {-value } \\
\text { GOLD } 2 \text { vs } \\
\text { controls }\end{array}$ & $\begin{array}{l}\text { P-value } \\
\text { GOLD I vs } \\
\text { GOLD } 2\end{array}$ \\
\hline Age (years) & $64.5 \pm 9.0$ & $66.4 \pm 9.9$ & $63.9 \pm 8.8$ & 0.221 & 0.361 & 0.895 & 0.234 \\
\hline Male, n (\%) & $73(6 I)$ & $54(77)$ & $39(53)$ & 0.007 & 0.023 & 0.238 & 0.002 \\
\hline BMI $\left(\mathrm{kg} / \mathrm{m}^{2}\right)$ & $27.2 \pm 4.9$ & $26.3 \pm 3.6$ & $27.4 \pm 5.6$ & 0.322 & 0.484 & 0.908 & 0.331 \\
\hline Waist-to-hip ratio & $0.93 \pm 0.09$ & $0.94 \pm 0.07$ & $0.94 \pm 0.10$ & 0.403 & 0.464 & 0.573 & 0.987 \\
\hline Current smokers, n (\%) & $12(10)$ & $15(2 \mid)$ & $24(32)$ & 0.003 & 0.104 & 0.0004 & 0.247 \\
\hline Former smokers, n (\%) & 70 (59) & $37(53)$ & $37(50)$ & & & & \\
\hline Never smokers, n (\%) & $37(31)$ & $18(26)$ & $13(18)$ & & & & \\
\hline Pack/year & $16 \pm 18$ & $2 I \pm 24$ & $37 \pm 29$ & $<0.001$ & $<0.334$ & $<0.001$ & $<0.001$ \\
\hline \multicolumn{8}{|l|}{ Pulmonary function } \\
\hline Post-BD FEV, (L) & $2.95 \pm 0.79$ & $2.80 \pm 0.74$ & $1.79 \pm 0.63$ & $<0.001$ & 0.409 & $<0.001$ & $<0.001$ \\
\hline Post-BD, FEV , \% predicted & $102 \pm 13$ & $95 \pm 12$ & $64 \pm 13$ & $<0.001$ & $<0.001$ & $<0.001$ & $<0.001$ \\
\hline Post-BD FVC (L) & $3.83 \pm 1.04$ & $4.37 \pm 1.10$ & $3.17 \pm 0.96$ & $<0.003$ & $<0.001$ & $<0.001$ & $<0.001$ \\
\hline Post-BD FVC, \% predicted & $122 \pm 17$ & $136 \pm 22$ & $104 \pm 18$ & $<0.001$ & $<0.001$ & $<0.001$ & $<0.001$ \\
\hline Post-BD FEV,/FVC, \% & $77 \pm 4$ & $64 \pm 5$ & $56 \pm 9$ & $<0.001$ & $<0.001$ & $<0.001$ & $<0.001$ \\
\hline \multicolumn{8}{|l|}{ Medication at baseline } \\
\hline Short-acting BD, n (\%) & $2(1.7)$ & $5(7.1)$ & $19(26.7)$ & $<0.001$ & 0.060 & $<0.001$ & 0.002 \\
\hline Long-acting BD, n (\%) & I (0.8) & $0(0)$ & I (I.4) & 0.5075 & 0.335 & 0.737 & 0.247 \\
\hline Inhaled CS, n (\%) & $3(0.3)$ & $7(10.0)$ & $26(35.1)$ & $<0.001$ & 0.030 & $<0.001$ & $<0.001$ \\
\hline ACE/ARB, n (\%) & $22(18.4)$ & $14(20.0)$ & $23(31.1)$ & 0.117 & 0.799 & 0.046 & 0.127 \\
\hline$\beta$-Blockers, n (\%) & $9(7.6)$ & $4(5.7)$ & $10(13.5)$ & 0.228 & 0.623 & 0.183 & 0.109 \\
\hline Statins, n (\%) & $28(23.5)$ & I8 (25.7) & $20(27.0)$ & 0.854 & 0.736 & 0.586 & 0.858 \\
\hline Other hypolipidemic drugs, n (\%) & $4(3.3)$ & I (I.4) & $2(2.7)$ & 0.704 & 0.403 & 0.796 & 0.589 \\
\hline Oral hypoglycemic agents, n (\%) & $9(7.6)$ & $4(5.7)$ & $6(8.1)$ & 0.836 & 0.623 & 0.891 & 0.571 \\
\hline
\end{tabular}

Notes: a $V$ alues are mean \pm SD. ${ }^{b}$-test for the global effect of group GOLD with post hoc comparisons done with protected LSD.

Abbreviations: GOLD, Global initiative for chronic Obstructive Lung Disease; ACE, angiotensin-converting enzyme inhibitors; ARB, angiotensin II receptor blockers; $\mathrm{BD}$, bronchodilator; BMI, body mass index; CS, corticosteroids; LSD, least significant difference method. 
the subgroups. The proportion of individuals showing cardiometabolic comorbidities within each group was compared using a chi-squared test. Logistic regression models were used to document possible associations between cardiometabolic comorbidities (diabetes, hypertension, coronary artery disease, peripheral artery disease) as dependent variables and age, sex, cumulative tobacco exposure (pack-years), BMI, waist circumference, waist-to-hip ratio, $\mathrm{FEV}_{1} \%$ predicted, and body composition parameters (visceral adipose tissue cross-sectional area, visceral adipose tissue attenuation, subcutaneous adipose tissue cross-sectional area, subcutaneous adipose tissue attenuation, muscle tissue cross-sectional area, muscle tissue attenuation, liver attenuation) as independent variables. The strength of the models to predict the presence of a specific comorbidity was evaluated by computing the area under the receiver operating characteristic (ROC) curve (C-statistic), with value $>0.9$ (excellent), 0.80-0.90 (good), and $<0.80$ (fair). $P$-values $<0.05$ were considered statistically significant. Data analyses were performed using SAS version 9.4 (SAS Institute Inc., San Diego, CA, USA).
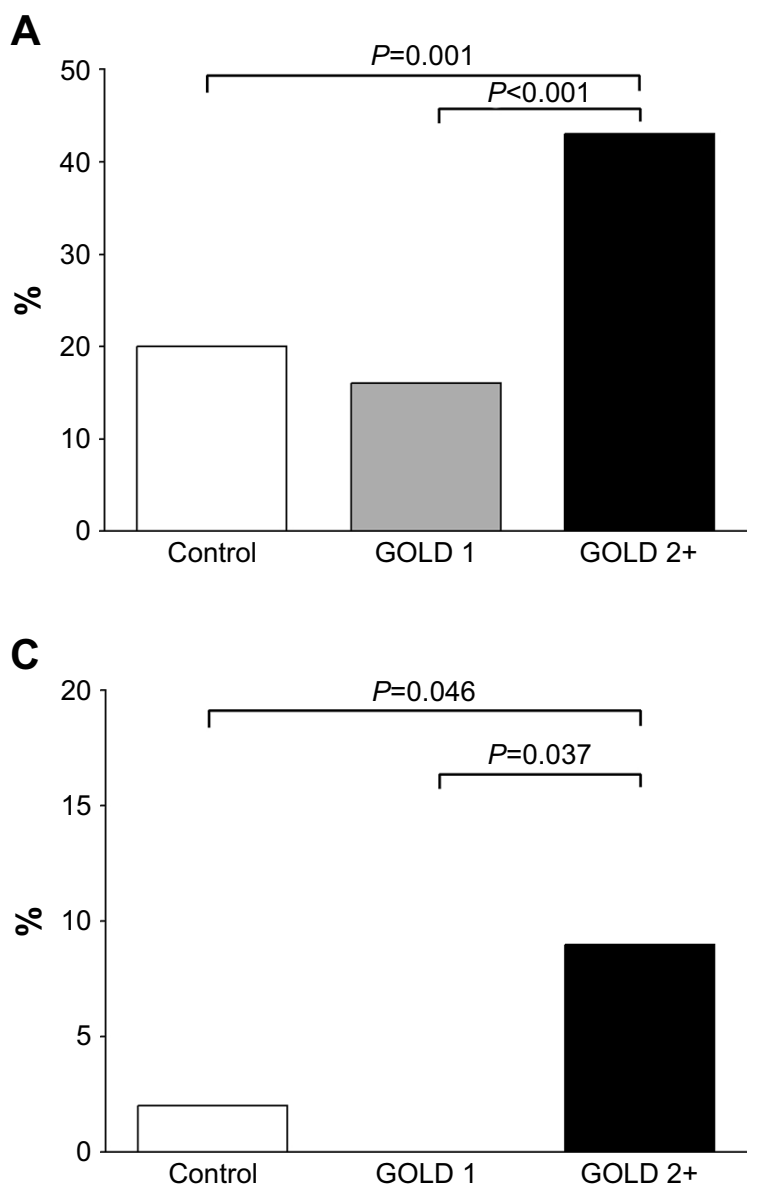

\section{Results}

This CanCOLD substudy included 263 participants with a mean age of $65 \pm 9$ years and, of whom, two-third were males (Table 1). Subjects were divided into control subjects with normal lung function $(n=119)$, and GOLD $1(n=70)$ and GOLD 2+ $(n=74)$ individuals with COPD. There were no statistically significant between-subgroup differences for age, BMI, and waist-to-hip ratio (Table 1). The proportion of men was greater in GOLD 1 compared to the other two groups. The proportion of current smokers was greater in GOLD 2+ vs controls, while the cumulative tobacco exposure was greater in GOLD 2+ compared to controls and GOLD 1 patients.

Comorbidities at study entry and blood glucose, lipid, and adipokine profiles are presented in Figure 1 and Table 2, respectively. The prevalence of hypertension and coronary artery disease was greater in GOLD 2+ subjects compared to GOLD 1 and controls. Blood glucose, lipid, and adipokine profiles were similar across groups with the exception of leptin level which was higher in GOLD 2+ subjects compared to GOLD 1 and controls. There was a tendency

B

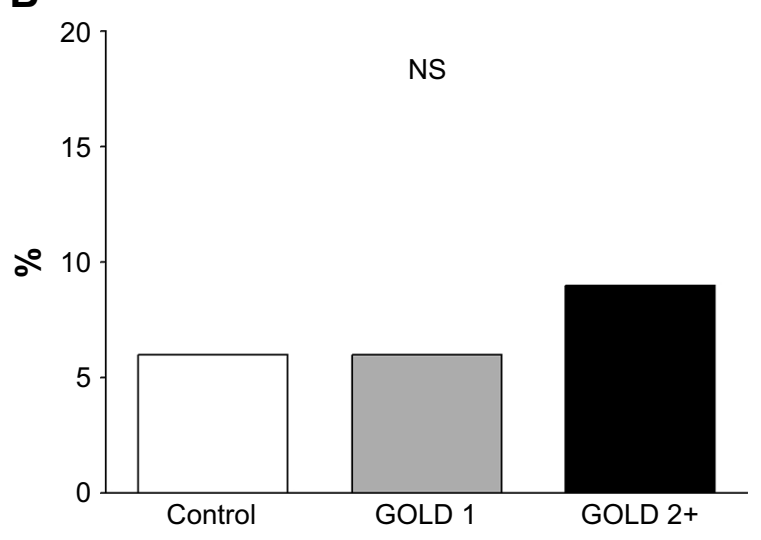

D

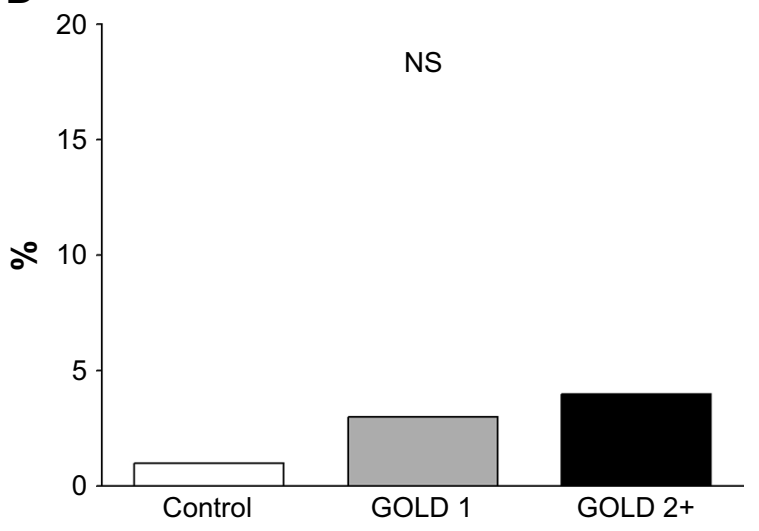

Figure I Proportion of subjects in each group with a diagnosis of hypertension (A), diabetes, (B), coronary artery disease (C), and peripheral artery disease (D). Abbreviations: GOLD, Global initiative for chronic Obstructive Lung Disease; NS, not significant. 
Table 2 Blood glucose, lipid, adipokine, and Hs-CRP profiles ${ }^{\mathrm{a}}$

\begin{tabular}{|c|c|c|c|c|c|c|c|}
\hline & $\begin{array}{l}\text { Control } \\
\text { subjects } \\
(n=I \mid 9)\end{array}$ & $\begin{array}{l}\text { GOLD I } \\
\text { COPD } \\
(n=70)\end{array}$ & $\begin{array}{l}\text { GOLD } 2 \\
\text { COPD } \\
(n=74)\end{array}$ & $\begin{array}{l}P \text {-value } \\
\text { Overallb }^{\mathrm{b}}\end{array}$ & $\begin{array}{l}\text { P-value } \\
\text { GOLD I vs } \\
\text { controls }\end{array}$ & $\begin{array}{l}\text { P-value } \\
\text { GOLD } 2 \text { vs } \\
\text { controls }\end{array}$ & $\begin{array}{l}P \text {-value } \\
\text { GOLD I vs } \\
\text { GOLD } 2\end{array}$ \\
\hline Glucose (mmol/L) & $5.8 \pm 1.3$ & $5.7 \pm 1.3$ & $6.0 \pm 1.4$ & 0.268 & 0.483 & 0.285 & 0.106 \\
\hline Insulin (pmol/L) & $130 \pm 168$ & $117 \pm 170$ & $120 \pm 176$ & 0.859 & 0.616 & 0.700 & 0.931 \\
\hline HBAIC (\%) & $5.7 \pm 0.6$ & $5.6 \pm 0.6$ & $5.8 \pm 0.6$ & 0.120 & 0.327 & 0.170 & 0.040 \\
\hline Total cholesterol $(\mathrm{mmol} / \mathrm{L})$ & $4.89 \pm 1.13$ & $5.11 \pm 1.14$ & $4.92 \pm 1.19$ & 0.400 & 0.184 & 0.831 & 0.343 \\
\hline LDL-cholesterol (mmol/L) & $2.77 \pm 1.00$ & $2.96 \pm 1.01$ & $2.74 \pm 1.05$ & 0.375 & 0.218 & 0.845 & 0.218 \\
\hline HDL-cholesterol (mmol/L) & $1.47 \pm 0.45$ & $\mathrm{I} .5 \mathrm{I} \pm 0.45$ & $1.54 \pm 0.47$ & 0.624 & 0.535 & 0.360 & 0.777 \\
\hline Triglycerides (mmol/L) & $1.43 \pm 0.73$ & $1.42 \pm 0.74$ & $1.44 \pm 0.77$ & 0.994 & 0.986 & 0.926 & 0.922 \\
\hline Apolipoprotein B (g/L) & $0.92 \pm 0.25$ & $0.92 \pm 0.26$ & $0.92 \pm 0.27$ & 0.977 & 0.836 & 0.987 & 0.870 \\
\hline Apolipoprotein AI (g/L) & $1.56 \pm 0.28$ & $1.59 \pm 0.28$ & $1.63 \pm 0.29$ & 0.224 & 0.473 & 0.09 & 0.356 \\
\hline GGT (U/L) & $29.8 \pm 26.3$ & $23.2 \pm 26.7$ & $29.3 \pm 27.7$ & 0.231 & 0.101 & 0.910 & 0.191 \\
\hline $\operatorname{ALT}(\mathrm{U} / \mathrm{L})$ & $20.9 \pm 10.2$ & $18.2 \pm 10.1$ & $22.2 \pm 10.7$ & 0.065 & 0.076 & 0.413 & 0.025 \\
\hline AST (U/L) & $24.7 \pm 7.3$ & $23.2 \pm 7.34$ & $25.5 \pm 7.7$ & 0.218 & 0.207 & 0.487 & 0.090 \\
\hline Leptin (ng/mL) & $|2.1 \pm 1| .4$ & $9.0 \pm 11.6$ & $14.3 \pm 12.0$ & 0.033 & 0.078 & 0.229 & 0.010 \\
\hline Adiponectin (ng/mL) & $7.7 \pm 4.8$ & $9.1 \pm 4.9$ & $9.0 \pm 5.0$ & 0.098 & 0.068 & 0.087 & 0.966 \\
\hline Leptin/adiponectin & $2.28 \pm 2.89$ & $|.32 \pm 2.9|$ & $2.33 \pm 3.01$ & 0.057 & 0.027 & 0.905 & 0.046 \\
\hline Resistin (ng/mL) & $6.98 \pm 3.15$ & $6.91 \pm 3.19$ & $7.00 \pm 3.30$ & 0.984 & 0.883 & 0.970 & 0.873 \\
\hline Ghrelin (pg/mL) & $55 I \pm 65 I$ & $656 \pm 663$ & $670 \pm 685$ & 0.407 & 0.294 & 0.254 & 0.906 \\
\hline Hs-CRP (mg/L) & $1.82 \pm 3.11$ & $1.91 \pm 3.15$ & $3.38 \pm 3.26$ & 0.004 & 0.845 & 0.002 & 0.007 \\
\hline
\end{tabular}

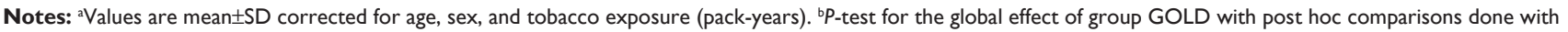
protected LSD.

Abbreviations: ALT, alanine aminotransferase; AST, aspartate aminotransferase; GGT, gamma glutamyl-transferase; GOLD, Global initiative for chronic Obstructive Lung Disease; HBAIC, glycosylated hemoglobin; Hs-CRP, high-sensitivity C-reactive protein.

for hemoglobin A1c to be higher in GOLD 2+ subjects compared to GOLD 1 subjects; this difference should be interpreted cautiously because the overall $P$-values from the MANCOVA analysis did not reach the 0.05 statistical threshold. Hs-CRP levels were higher in GOLD 2+ subjects in comparison to controls and GOLD 1.

BMI, waist-to-hip ratio, and CT-derived indices of body composition are depicted in Figure 2. Despite exhibiting similar BMI and waist-to-hip ratio, subjects with GOLD 2+ COPD had a higher visceral adipose tissue cross-sectional area than subjects with GOLD 1 COPD $(P=0.004)$. Consistent with these observations, mean muscle tissue attenuation was lower in GOLD 2+ vs the other groups, while muscle tissue cross-sectional area was similar across groups. Subcutaneous adipose tissue cross-sectional area was similar across groups. GOLD 1 individuals had a lower visceral adipose tissue cross-sectional area than controls $(P=0.048)$, whereas the mean muscle tissue attenuation was similar between these two groups. Coronary artery calcification burden, assessed either by total score or by total volume, was similar across the three groups (Table 3). Similarly, hepatic density was also similar across groups.

Potential predictors of cardiometabolic comorbidities are presented in Table 4. CT-derived indices of ectopic adiposity emerged as strong predictors of hypertension, diabetes, and coronary artery disease, independent of age, sex, tobacco exposure, BMI, and waist-to-hip ratio (Table 4). Each $1-\mathrm{cm}^{2}$ increase in the cross-sectional area of visceral adipose tissues was associated with a $1 \%$ increase in the odds of having hypertension or diabetes (both $P<0.001$ ). Each 1 -HU increase in muscle tissue attenuation was associated with a $25 \%$ reduction in the odds of having coronary artery disease $(P<0.001)$. According to the $\mathrm{C}$-statistic, the predictive ability of the models was good to excellent (all three areas under the ROC curve $>0.8$ ). No model could properly predict peripheral artery disease.

\section{Discussion}

This CanCOLD substudy provides novel information about adiposity and its association with cardiometabolic health in COPD, which can be summarized as follows: 1) in comparison to GOLD 1, and after controlling for important risk factors, GOLD 2+ subjects featured increased ectopic fat accumulation as evidenced by increased visceral adipose tissue cross-sectional areas and reduced muscle tissue attenuation, a marker of muscle fat infiltration; 2) CT body composition parameters indicative of ectopic fat accumulation were associated with the presence of hypertension, diabetes, and coronary artery disease which were also more frequent in GOLD 2+ subjects, indicating that cardiometabolic health 
A

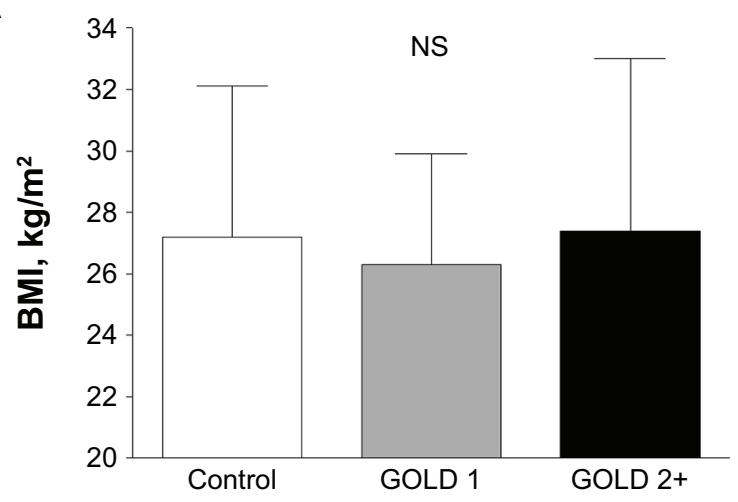

C

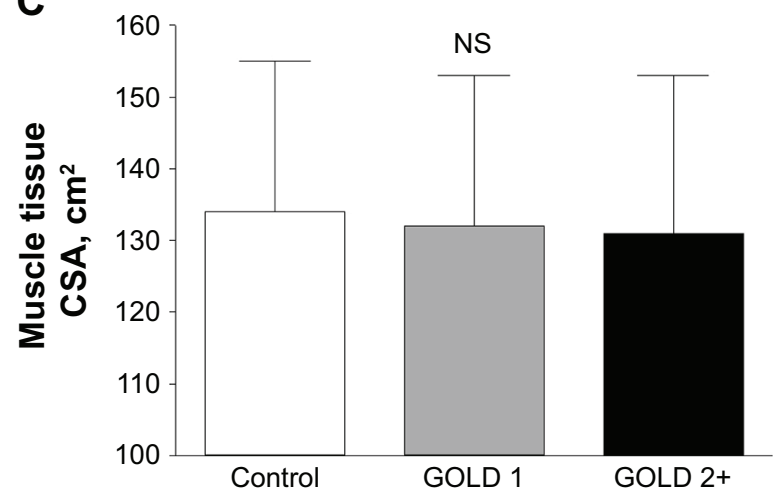

E

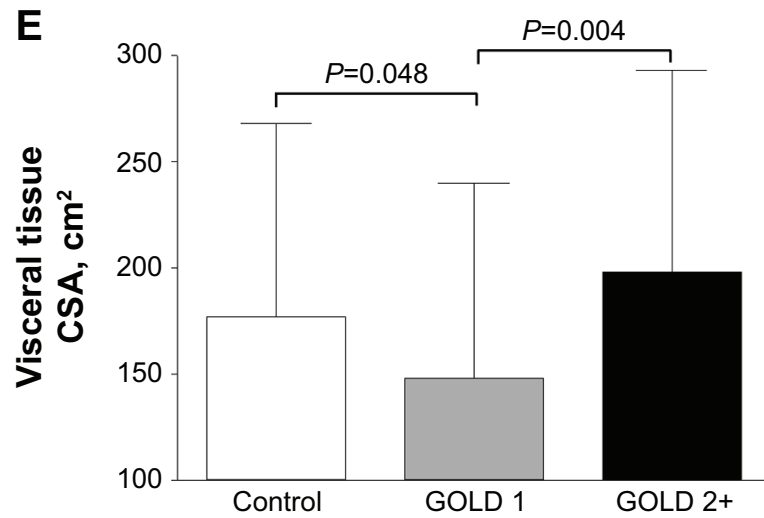

G

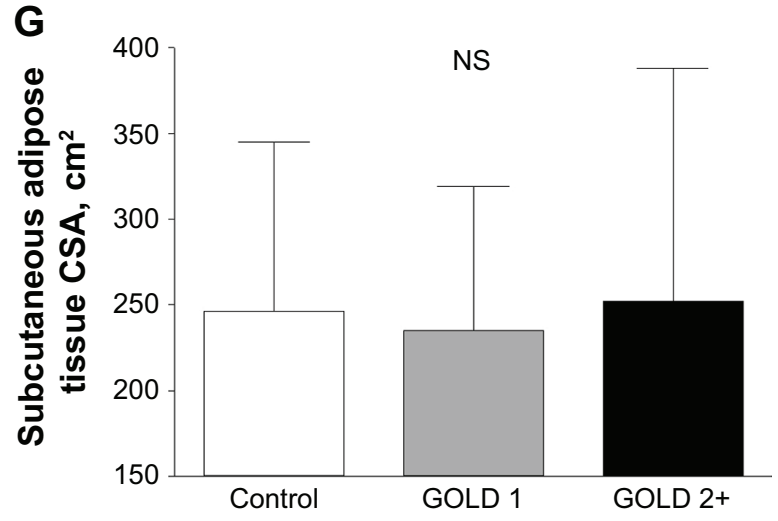

B

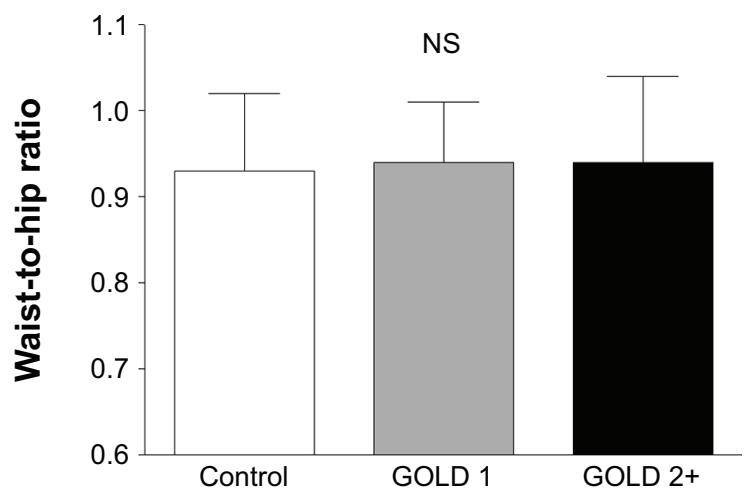

D

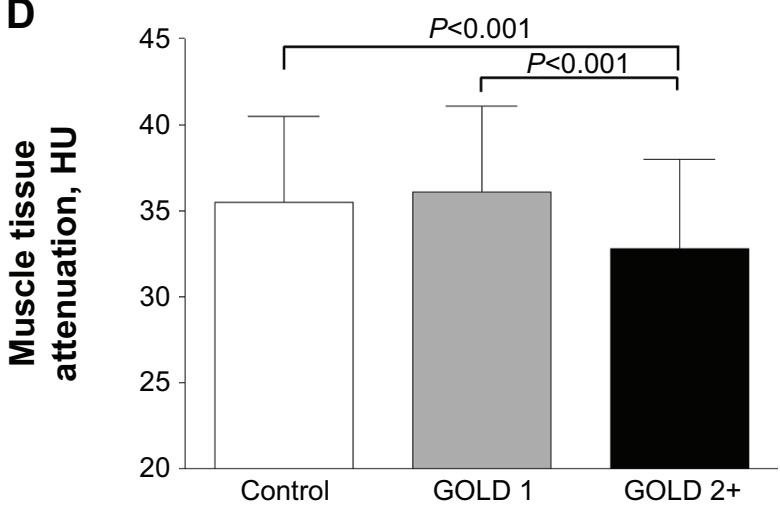

F

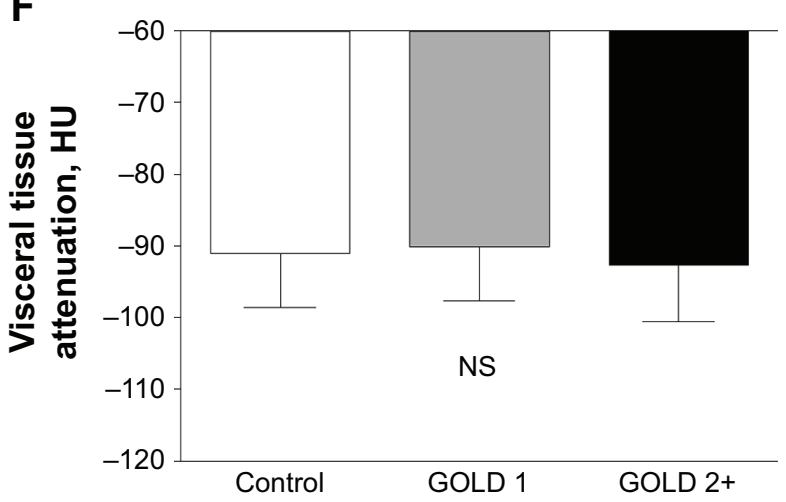

H

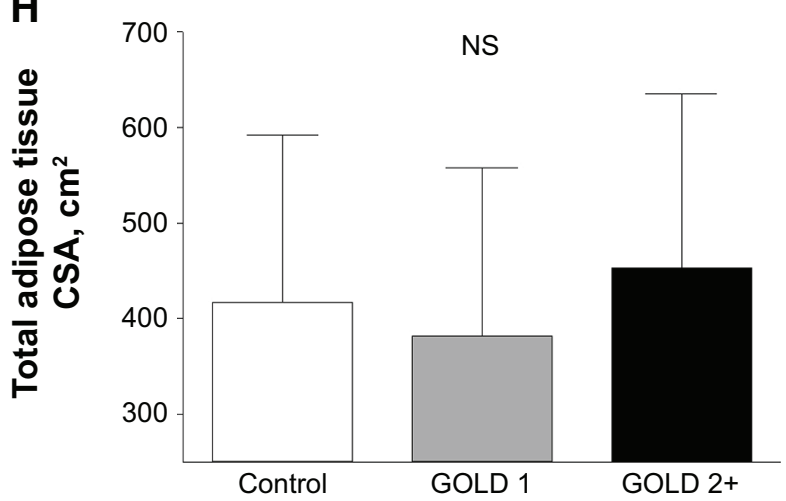

Figure 2 Group mean values \pm SD for body mass index (A), waist-to-hip ratio (B), muscle tissue cross-sectional area (muscle tissue CSA; C), muscle tissue attenuation (D), visceral adipose tissue CSA (E), visceral adipose tissue attenuation (F), subcutaneous adipose tissue CSA (G), and total adipose tissue CSA (H), in control subjects (open bars) and subjects with Global initiative for chronic Obstructive Lung Disease (GOLD) I (gray bars) and 2+ (black bars) COPD.

Abbreviations: NS, not significant; CSA, cross-sectional tissue area; HU, Hounsfield units. 
Table 3 Coronary artery calcification and liver density

\begin{tabular}{|c|c|c|c|c|c|c|c|}
\hline & $\begin{array}{l}\text { Control } \\
\text { subjects } \\
(n=I \mid 9)\end{array}$ & $\begin{array}{l}\text { GOLD I } \\
\text { COPD } \\
(n=70)\end{array}$ & $\begin{array}{l}\text { GOLD } 2 \\
\text { COPD } \\
(n=74)\end{array}$ & $\begin{array}{l}P \text {-value } \\
\text { Overall }^{b}\end{array}$ & $\begin{array}{l}\text { P-value } \\
\text { GOLD I vs } \\
\text { controls }\end{array}$ & $\begin{array}{l}P \text {-value } \\
\text { GOLD } 2 \text { vs } \\
\text { controls }\end{array}$ & $\begin{array}{l}P \text {-value } \\
\text { GOLD I vs } \\
\text { GOLD } 2\end{array}$ \\
\hline \multicolumn{8}{|l|}{ Coronary artery calcification } \\
\hline Agatston total calcium score & $352 \pm 512$ & $270 \pm 520$ & $342 \pm 550$ & 0.557 & 0.294 & 0.911 & 0.429 \\
\hline Agatston total calcium volume & $287 \pm 4 I I$ & $223 \pm 417$ & $283 \pm 442$ & 0.607 & 0.337 & 0.946 & 0.451 \\
\hline \multicolumn{8}{|l|}{ Fat liver infiltration } \\
\hline Liver density (HU) & $58.4 \pm 10.0$ & $59.1 \pm 10.0$ & $58.2 \pm 10.4$ & 0.866 & 0.655 & 0.905 & 0.622 \\
\hline
\end{tabular}

Notes: ${ }^{\vee}$ alues are mean \pm SD corrected for age, sex, and tobacco exposure (pack-years). ${ }^{b}$-test for the global effect of group GOLD with post hoc comparisons done with protected LSD.

Abbreviations: GOLD, Global initiative for chronic Obstructive Lung Disease; HU, Hounsfield units; LSD, least significant difference method.

is intimately linked to body composition abnormalities in this population; and 3) the observation that visceral adipose tissues accumulate and that cardiometabolic comorbidities are more frequent in GOLD 2+ COPD subjects supports the notion that chronic diseases have a natural tendency to cluster within the same individuals.

A key methodological feature of this study is that participants were identified through random population sampling, and not from previous contact with medical teams or by advertising. The latter two recruitment strategies would likely lead to study enrollment of individuals having more important disease manifestations, which may not be representative of the general population. This could potentially bias conclusions regarding the association between ectopic adiposity, cardiometabolic comorbidities, and COPD. It has been shown that the burden of multimorbidity is greater in patients attending clinical care compared to the general population. ${ }^{20}$ The clustering of ectopic fat accumulation, cardiometabolic comorbidities, and COPD found in the present random population sampling study is reflective of possible mechanistic associations between these conditions rather than the fact that individuals reaching medical care for one condition are more likely to be found with a second condition.

The present study offers a unique opportunity to evaluate the occurrence of ectopic adiposity and cardiometabolic comorbidities in mild COPD, and provides complementary information to large COPD cohort studies involving patients with more advanced diseases, such as ECLIPSE and COPDGene. ${ }^{21,22}$ We demonstrated that individuals with GOLD 1 COPD did not feature increased ectopic adiposity and cardiometabolic comorbidities compared to controls with normal lung function. Although the cross-sectional nature of the present study does not allow to reach a firm conclusion on the direction of the association between COPD and ectopic adiposity, the similarity in ectopic fat accumulation between GOLD 1 COPD and controls suggests that the development of overt airflow limitation precedes that of ectopic adiposity and cardiometabolic comorbidities. These results are in agreement with a study involving subjects newly diagnosed with COPD who were identified through lung cancer screening. ${ }^{23}$

Although CanCOLD was not designed to investigate in a mechanistic way the nature of the association between

Table 4 Predictors of cardiovascular comorbidities in multiple regression analyses

\begin{tabular}{|c|c|c|c|c|c|c|}
\hline & Estimate & SE & $\begin{array}{l}\text { Odds } \\
\text { ratio }\end{array}$ & $95 \% \mathrm{Cl}$ & $P$-value & C-statistic \\
\hline Hypertension & & & & & & 0.83 \\
\hline VAT CSA $\left(\mathrm{cm}^{2}\right)$ & 0.011 & 0.002 & 1.011 & $1.007-1.015$ & $<0.001$ & \\
\hline Age (years) & 0.093 & 0.021 & 1.097 & $1.053-1.142$ & $<0.001$ & \\
\hline Post BD, $\mathrm{FEV}_{1}, \%$ predicted & -0.020 & 0.008 & 0.981 & $0.965-0.997$ & 0.0177 & \\
\hline Diabetes & & & & & & 0.83 \\
\hline VAT CSA $\left(\mathrm{cm}^{2}\right)$ & 0.010 & 0.002 & 1.010 & $1.006-1.014$ & $<0.00$ I & \\
\hline SCAT attenuation (HU) & 0.067 & 0.027 & 1.070 & $1.016-1.127$ & 0.002 & \\
\hline Age (years) & 0.059 & 0.026 & 1.060 & $1.009-1.115$ & 0.0216 & \\
\hline Coronary artery disease & & & & & & 0.86 \\
\hline MT attenuation $(\mathrm{HU})$ & -0.276 & 0.069 & 0.759 & $0.662-0.869$ & $<0.00$ I & \\
\hline Sex, male & 3.042 & 1.111 & 20.9 & $2.4-185$ & 0.0062 & \\
\hline
\end{tabular}

Abbreviations: $\mathrm{BD}$, bronchodilator; $\mathrm{C}$-statistic, area under the ROC curve; ROC, receiver operating characteristic; VAT, visceral adipose tissue; FEV ${ }_{1}$, forced expiratory volume in I s; CSA, cross-sectional tissue area; HU, Hounsfield units; MT, muscle tissue; SCAT, subcutaneous adipose tissue. 
COPD, ectopic adiposity, and cardiometabolic comorbidities, the current findings may point toward certain possible pathophysiological scenarios of association, including shared risk factors such as aging, smoking, sedentary lifestyle, and poor nutritional habits. All analyses concerning these associations were adjusted for age, sex, and tobacco exposure, suggesting that the relationship among ectopic adiposity, cardiometabolic health, and COPD goes beyond these risk factors. Sedentary lifestyle that accompanies COPD progression $^{24}$ appears as an interesting intermediate link between COPD and ectopic adiposity ${ }^{25,26}$ but this factor was not explored in the present study. It is also conceivable that common pathophysiological pathways exist to favor the development of COPD and ectopic obesity, including genetic predisposition and generic responses to biological stresses such as low-grade chronic inflammation state. ${ }^{27}$ Irrespective of the mechanisms, our data suggested that the development of ectopic adiposity and cardiometabolic comorbidities in individuals with COPD requires a certain degree of disease severity/activity that was evidenced in our population by more advanced airflow limitation and increased Hs-CRP levels.

Apart from the population sampling method, our study has other strengths. First, it was specifically designed to address the study questions in a prospective fashion and all participants in both centers contributing to the recruitment completed the specific evaluations related to the exploration of body fat distribution. Cardiometabolic profiling was also rather extensive, providing novel information on this topic. Increased ectopic adiposity in GOLD 2+ individuals was not associated with altered lipid profiles, perhaps due to the high proportion of participants on hypolipidemic agents. Higher leptin and Hs-CRP levels and the tendency for elevated hemoglobin A1C in GOLD 2+ subjects were consistent with the accumulation of visceral fat and higher cardiometabolic risk in GOLD 2+ individuals. ${ }^{4}$

One potential limiting factor, however, is the fact that the study was limited to two CanCOLD centers. It would nevertheless be of interest to examine if the current findings also apply to the larger CanCOLD population. Another limitation is the cross-sectional nature of the data collection. The longitudinal follow-up of CanCOLD is currently in progress and this will eventually allow studying the interactions between the longitudinal changes in body composition and cardiometabolic health in this population. We acknowledge that comorbidities were only assessed from standardized questionnaires and current medications and not from objectively measured physiological or biological criteria. Despite its limitations, this method of assessing comorbidities has been previously validated $^{28}$ and is used in large epidemiological studies. ${ }^{29}$
Obesity is now the most common body composition abnormality in COPD. ${ }^{1,2}$ COPD is also commonly associated with cardiovascular diseases, ${ }^{30}$ hypertension, ${ }^{31}$ metabolic syndrome, ${ }^{32,33}$ and diabetes. ${ }^{34} \mathrm{We}$ also know that cardiovascular diseases are an important cause of mortality in COPD. ${ }^{6,12}$ As such, cardiometabolic health should be a primary concern in patients with COPD and further work should be conducted to investigate how to best improve this important aspect of general health in patients with COPD. ${ }^{35}$

Excess ectopic adiposity has been pathologically associated with the development of cardiometabolic disorders in the general population. ${ }^{4}$ Likewise, we report that body composition parameters are associated with cardiometabolic comorbidities in this population of subjects with COPD. Similar findings were also reported from the ECLIPSE cohort. ${ }^{5}$ We extend these findings by reaching similar conclusion in patients with milder form of COPD, highlighting the necessity of addressing early in the disease process the issue of cardiometabolic health in COPD.

Cardiometabolic consequences of obesity are largely attributable to an excess of ectopic adipose tissue accumulating in the abdomen, rather than to subcutaneous "healthy" fat accumulation. ${ }^{4}$ Our findings that indices of fat distribution, and not BMI, predict of cardiometabolic comorbidities are in agreement with these notions. Increased ectopic adiposity in GOLD 2+ individuals was not evidenced by "traditional" clinical measures such as BMI or waist-to-hip ratio which were similar across the groups. These findings may have implications about how cardiometabolic health is evaluated in COPD. Another interesting finding is the association between intra-abdominal muscle density and coronary artery disease, which was also reported in ECLIPSE. ${ }^{5}$ Reduced muscle density in these two studies is consistent with the MRI evidence of intramuscular fat accumulation in COPD reported by other investigators. ${ }^{36,37}$ Ectopic fat accumulation in the skeletal muscle may influence muscle metabolism, leading to a cascade of reduced fat oxidation and insulin resistance, linking muscle metabolic abnormalities to cardiovascular comorbidities. ${ }^{38}$

A notable negative finding of this study is the absence of increased coronary artery calcification in subjects with COPD compared with controls. This finding is at variance with previous reports from ECLIPSE. 5,39 This discrepancy between studies may lie in differences in how participants were recruited and in the severity of airflow limitation in study participants; for example, ECLIPSE mostly involved subjects with GOLD 2-4 COPD. Furthermore, coronary artery calcification reflects only one aspect of coronary artery disease. It is possible that the well-established link 
between ectopic adiposity and coronary artery disease involves other aspects such as the atherosclerotic plaque composition and fragility to rupture. Considering the general association of intra-abdominal fat accumulation with liver fat accumulation, ${ }^{40}$ we expected to find reduced liver density in GOLD 2+ COPD individuals compared to controls. However, the association between intra-abdominal fat accumulation and liver fatty infiltration is not universal as dissociation could exist between these two fat depots. ${ }^{41}$

\section{Conclusion}

Our study, based on random population sampling confirms a strong association between ectopic fat accumulation and impaired cardiometabolic health in COPD. These findings point to a clustering of chronic respiratory and cardiometabolic diseases in susceptible individuals and to the necessity of addressing cardiometabolic health early in the disease process of individuals with COPD.

\section{Acknowledgments}

The authors thank Cynthia Brouillard (Institut Universitaire de Cardiologie et de Pneumologie de Québec, QC, Canada), Palmina Mancino, David Latreille, Jacinthe Baril, Laura Labonté (Research Institute of the McGill University Health Center, Montreal, QC, Canada) who were responsible for the clinical evaluation of study participants, Véronic Tremblay from the body composition analysis platform of the Institut Universitaire de cardiologie et de pneumologie de Québec for ensuring standardization of the CT images analyses, Nathalie Mercier and Karine Bibeau for quantifying coronary artery calcifications, Sylvain Pouliot who analyzed the metabolic and adipokine profiles, and Gaétan Daigle for statistical assistance. They also thank all the subjects, investigators, and study site staff who participated in CanCOLD.

The Canadian Cohort Obstructive Lung Disease (CanCOLD) study is currently funded by the Canadian Respiratory Research Network (industry partners: Astra Zeneca Canada Ltd., Boehringer Ingelheim Canada Ltd., GlaxoSmithKline Canada Ltd., and Novartis). Previous funding partners were the CIHR (CIHR/Rx\&D Collaborative Research Program Operating Grants-93326) and the Respiratory Health Network of the FRSQ (industry partners: Almirall, Merck Nycomed, Pfizer Canada Ltd., and Thera technologies). J-PD is the scientific director of the International Chair on Cardiometabolic Risk which is based at the Faculty of medicine, Université Laval. EL is a research scholar from the Fonds de Recherche Québec - Santé (FRQS). JB holds a GSK/CIHR Research Chair on COPD at McGill University. FM holds a GSK/CIHR Research Chair on COPD at Université Laval.

\section{Disclosure}

The authors report no conflicts of interest in this work.

\section{References}

1. Sava F, Laviolette L, Bernard S, Breton MJ, Bourbeau J, Maltais F. The impact of obesity on walking and cycling performance and response to pulmonary rehabilitation in COPD. BMC Pulm Med. 2010;10:55.

2. Rutten EP, Calverley PM, Casaburi R, et al. Changes in body composition in patients with chronic obstructive pulmonary disease: do they influence patient-related outcomes? Ann Nutr Metab. 2013;63(3):239-247.

3. Tchernof A, Després JP. Pathophysiology of human visceral obesity: an update. Physiol Rev. 2013;93(1):359-404.

4. Després JP, Lemieux I. Abdominal obesity and metabolic syndrome. Nature. 2006;444(7121):881-887.

5. Martin M, Alméras N, Després JP, et al. Ectopic fat accumulation in patients with COPD: an ECLIPSE substudy. Int J Chron Obstruct Pulmon Dis. 2017;12:451-460.

6. van den Borst B, Gosker HR, Koster A, et al. The influence of abdominal visceral fat on inflammatory pathways and mortality risk in obstructive lung disease. Am J Clin Nutr. 2012;96(3):516-526.

7. Furutate R, Ishii T, Wakabayashi R, et al. Excessive visceral fat accumulation in advanced chronic obstructive pulmonary disease. Int $J$ Chron Obstruct Pulmon Dis. 2011;6:423-430.

8. Roversi S, Fabbri LM, Sin DD, Hawkins NM, Agustí A. Chronic Obstructive Pulmonary Disease and Cardiac Diseases. An Urgent Need for Integrated Care. Am J Respir Crit Care Med. 2016;194(11):1319-1336.

9. Chen W, Thomas J, Sadatsafavi M, Fitzgerald JM. Risk of cardiovascular comorbidity in patients with chronic obstructive pulmonary disease: a systematic review and meta-analysis. Lancet Respir Med. 2015;3(8): 631-639.

10. Bolton $\mathrm{CE}$, Evans $\mathrm{M}$, Ionescu $\mathrm{AA}$, et al. Insulin resistance and inflammation - A further systemic complication of COPD. COPD. 2007;4(2):121-126.

11. Hersh CP, Make BJ, Lynch DA, et al. Non-emphysematous chronic obstructive pulmonary disease is associated with diabetes mellitus. BMC Pulm Med. 2014;14:164.

12. Vestbo J, Anderson JA, Brook RD, et al. Fluticasone furoate and vilanterol and survival in chronic obstructive pulmonary disease with heightened cardiovascular risk (SUMMIT): a double-blind randomised controlled trial. Lancet. 2016;387(10030):1817-1826.

13. Bourbeau J, Tan WC, Benedetti A, et al. Canadian Cohort Obstructive Lung Disease (CanCOLD): Fulfilling the need for longitudinal observational studies in COPD. COPD. 2014;11(2):125-132.

14. Després JP, Ross R, Boka G, Alméras N, Lemieux I; ADAGIO-Lipids Investigators. Effect of rimonabant on the high-triglyceride/low-HDLcholesterol dyslipidemia, intraabdominal adiposity, and liver fat: the ADAGIO-Lipids trial. Arterioscler Thromb Vasc Biol. 2009;29(3):416-423.

15. Baba S, Jacene HA, Engles JM, Honda H, Wahl RL. CT Hounsfield units of brown adipose tissue increase with activation: preclinical and clinical studies. J Nucl Med. 2010;51(2):246-250.

16. Tan WC, Hague CJ, Leipsic J, et al. Findings on Thoracic Computed Tomography Scans and Respiratory Outcomes in Persons with and without Chronic Obstructive Pulmonary Disease: A Population-Based Cohort Study. PLoS One. 2016;11(11):e0166745.

17. Lee SS, Park SH. Radiologic evaluation of nonalcoholic fatty liver disease. World J Gastroenterol. 2014;20(23):7392-7402.

18. Alluri K, Joshi PH, Henry TS, Blumenthal RS, Nasir K, Blaha MJ. Scoring of coronary artery calcium scans: history, assumptions, current limitations, and future directions. Atherosclerosis. 2015;239(1):109-117.

19. Smith JD, Borel AL, Nazare JA, et al. Visceral adipose tissue indicates the severity of cardiometabolic risk in patients with and without type 2 diabetes: results from the INSPIRE ME IAA study. $J$ Clin Endocrinol Metab. 2012;97(5):1517-1525.

20. Mokraoui NM, Haggerty J, Almirall J, Fortin M. Prevalence of selfreported multimorbidity in the general population and in primary care practices: a cross-sectional study. BMC Res Notes. 2016;9:314. 
21. Agusti A, Calverley PM, Celli B, et al. Characterisation of COPD heterogeneity in the ECLIPSE cohort. Respir Res. 2010;11:122.

22. Wan ES, Hokanson JE, Murphy JR, et al. Clinical and radiographic predictors of GOLD-unclassified smokers in the COPDGene study. Am J Respir Crit Care Med. 2011;184(1):57-63.

23. van Remoortel H, Hornikx M, Langer D, et al. Risk factors and comorbidities in the preclinical stages of chronic obstructive pulmonary disease. Am J Respir Crit Care Med. 2014;189(1):30-38.

24. Troosters T, Sciurba F, Battaglia S, et al. Physical inactivity in patients with COPD, a controlled multi-center pilot-study. Respir Med. 2010; 104(7):1005-1011.

25. Henson J, Edwardson CL, Morgan B, et al. Associations of Sedentary Time with Fat Distribution in a High-Risk Population. Med Sci Sports Exerc. 2015;47(8):1727-1734.

26. Philipsen A, Hansen AL, Jørgensen ME, et al. Associations of objectively measured physical activity and abdominal fat distribution. Med Sci Sports Exerc. 2015;47(5):983-989.

27. Divo MJ, Martinez CH, Mannino DM. Ageing and the epidemiology of multimorbidity. Eur Respir J. 2014;44(4):1055-1068.

28. Katz JN, Chang LC, Sangha O, Fossel AH, Bates DW. Can comorbidity be measured by questionnaire rather than medical record review? Med Care. 1996;34(1):73-84.

29. Schnell K, Weiss CO, Lee T, et al. The prevalence of clinically-relevant comorbid conditions in patients with physician-diagnosed COPD: a cross-sectional study using data from NHANES 1999-2008. BMC Pulm Med. 2012;12:26.

30. Sin DD, Man SF, Sfp M. Why are patients with chronic obstructive pulmonary disease at increased risk of cardiovascular diseases? The potential role of systemic inflammation in chronic obstructive pulmonary disease. Circulation. 2003;107(11):1514-1519.

31. Vanfleteren LE, Spruit MA, Groenen M, et al. Clusters of comorbidities based on validated objective measurements and systemic inflammation in patients with chronic obstructive pulmonary disease. Am J Respir Crit Care Med. 2013;187(7):728-735.
32. Marquis K, Maltais F, Duguay V, et al. The metabolic syndrome in patients with chronic obstructive pulmonary disease. $J$ Cardiopulm Rehabil. 2005;25(4):226-232.

33. Breyer MK, Spruit MA, Hanson CK, et al. Prevalence of metabolic syndrome in COPD patients and its consequences. PLoS One. 2014;9(6): e98013.

34. Divo M, Cote C, de Torres JP, et al. Comorbidities and risk of mortality in patients with chronic obstructive pulmonary disease. Am J Respir Crit Care Med. 2012;186(2):155-161.

35. Cebron Lipovec N, Schols AM, van den Borst B, et al. Sarcopenia in Advanced COPD Affects Cardiometabolic Risk Reduction by ShortTerm High-intensity Pulmonary Rehabilitation. J Am Med Dir Assoc. 2016;17(9):814-820.

36. Maddocks M, Shrikrishna D, Vitoriano S, et al. Skeletal muscle adiposity is associated with physical activity, exercise capacity and fibre shift in COPD. Eur Respir J. 2014;44(5):1188-1198.

37. Robles PG, Sussman MS, Naraghi A, et al. Intramuscular Fat Infiltration Contributes to Impaired Muscle Function in COPD. Med Sci Sports Exerc. 2015;47(7):1334-1341.

38. Moon SS. Low skeletal muscle mass is associated with insulin resistance, diabetes, and metabolic syndrome in the Korean population: the Korea National Health and Nutrition Examination Survey (KNHANES) 2009-2010. Endocr J. 2014;61(1):61-70.

39. Williams MC, Murchison JT, Edwards LD, et al. Coronary artery calcification is increased in patients with COPD and associated with increased morbidity and mortality. Thorax. 2014;69(8):718-723.

40. Kelley DE, Mckolanis TM, Hegazi RA, Kuller LH, Kalhan SC. Fatty liver in type 2 diabetes mellitus: relation to regional adiposity, fatty acids, and insulin resistance. Am J Physiol Endocrinol Metab. 2003; 285(4):E906-E916.

41. Seppälä-Lindroos A, Vehkavaara S, Häkkinen AM, et al. Fat accumulation in the liver is associated with defects in insulin suppression of glucose production and serum free fatty acids independent of obesity in normal men. J Clin Endocrinol Metab. 2002;87(7):3023-3028.
International Journal of COPD

\section{Publish your work in this journal}

The International Journal of COPD is an international, peer-reviewed journal of therapeutics and pharmacology focusing on concise rapid reporting of clinical studies and reviews in COPD. Special focus is given to the pathophysiological processes underlying the disease, intervention programs, patient focused education, and self management protocols.

\section{Dovepress}

This journal is indexed on PubMed Central, MedLine and CAS. The manuscript management system is completely online and includes a very quick and fair peer-review system, which is all easy to use. Visit http://www.dovepress.com/testimonials.php to read real quotes from published authors. 